Original

\title{
Frequency of root resorption following trauma to permanent teeth
}

\author{
Adriana J. Soares'), Gustavo A. Souza ${ }^{2}$, Andrea C. Pereira'), Julio Vargas-Neto'), \\ Alexandre A. Zaia1), and Emmanuel J. N. L. Silva ${ }^{3}$ ) \\ 1)Department of Restorative Dentistry, Endodontics Area, \\ State University of Campinas, Piracicaba, SP, Brazil \\ 2)São Leopoldo Mandic Dental Research Center, Campinas, SP, Brazil \\ ${ }^{3)}$ Department of Endodontics, School of Dentistry, Health Sciences Center, Grande Rio University, \\ Rio de Janeiro, RJ, Brazil
}

(Received October 31, 2014; Accepted February 25, 2015)

\begin{abstract}
This retrospective study evaluated the frequency of development of root resorption in dental trauma cases involving supporting tissue. For 249 traumatized teeth of 125 patients aged between 7 and 51 years, we collected data on the gender and age of the patient, the teeth involved, the type of trauma, and the period between dental injury and initial examination. Radiographic parameters examined in relation to root resorption included the presence of inflammatory external root resorption, internal root resorption, replacement resorption, and canal calcification. Data were analyzed by chi-squared test, Fisher's exact test, and mult iple logistic regression $(P$ $<0.05$ ). The results indicated that there was a significant relationship between the period from the date of injury until initial examination and the occurrence of inflammatory external resorption $(P=\mathbf{0 . 0 1 9 9})$, as well as the type of injury $(P=0.0406)$. Furthermore, external resorption was most frequently associated with intrusive luxation (92.8\%), followed by avulsion (89.0\%), lateral luxation (80.2\%), and extrusive luxation (77.4\%). Among the types of dental injury, replacement resorption was observed more frequently in cases of avulsion (87.2\%). The only factor that was significantly associated with this type of resorption
\end{abstract}

Correspondence to Dr. Emmanuel João Nogueira Leal Silva, Rua Herotides de Oliveira, 61/902, 24230-230, Niterói, RJ, Brazil E-mail: nogueiraemmanuel@hotmail.com

doi.org/10.2334/josnusd.57.73

DN/JST.JSTAGE/josnusd/57.73 was the type of injury $(P<0.0001)$. Root resorption is observed more frequently and its risk of development is higher in cases of severe trauma, especially avulsion and intrusive luxation. (J Oral Sci 57, 73-78, 2015)

Keywords: endodontics; root resorption; tooth injury.

\section{Introduction}

In clinical practice, the frequency of patients presenting with dental injuries is quite high, with a reported annual incidence of between $1.5 \%$ and $2.8 \%(1,2)$. Such injuries are commonly related to falls, or traffic- or sport-related accidents (3-6). Dental injuries occur more frequently in children between 8 and 15 years of age, although lately there has been a reported increase among patients older than 18 years $(7,8)$. The majority of dental injuries involve the anterior teeth. In addition to hard dental tissues, the gingiva, periodontal tissues, dental pulp, and alveolar bone are often affected (3). Healing depends on factors such as the level of root development, the extent of damage to periodontal tissues, and the effects of bacterial contamination from the oral cavity. Trauma involving the supporting tissue, especially luxation and avulsion, is considered the most severe, and therefore sequelae resulting from neurovascular disruption, pulp necrosis, and bacterial contamination are more frequent. As complications may occur weeks, months, or even several years after injury, dental injuries require longterm follow-up (9-11).

One of the most frequent complications of these 


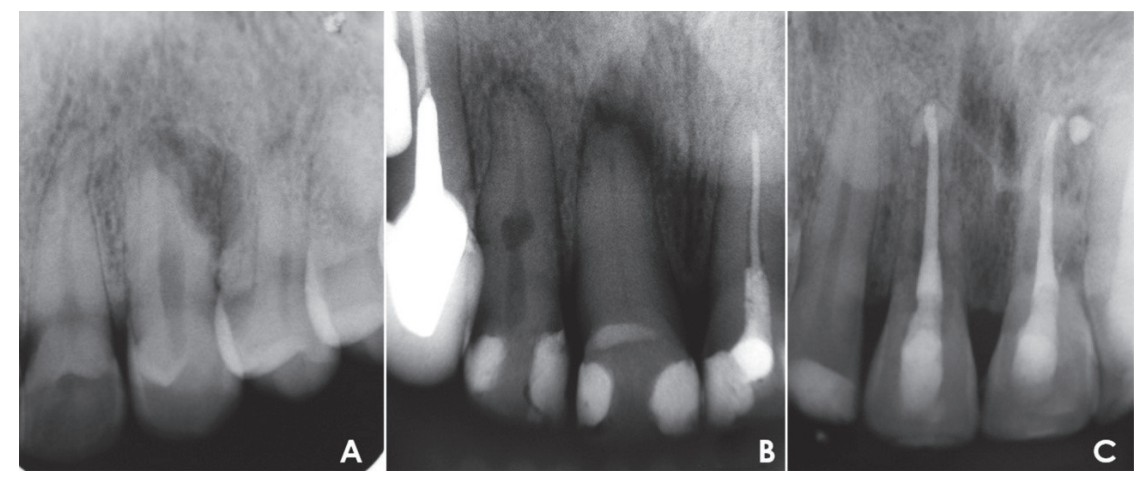

Fig. 1 Examples of root resorption evaluated in this study: A. External inflammatory root resorption; B. Internal inflammatory root resorption; C. Replacement resorption.

types of injury is root resorption. Root resorption is physiological in deciduous teeth, but is considered to be pathological in permanent dentition (12). Although the exact mechanisms responsible for root resorption are not fully understood (13), dental trauma is considered the major potential predisposing factor $(13,14)$. Other risk factors that have been identified as possible causes of root resorption include reactions to orthodontic treatment, necrotic tissue in the pulpal cavity, internal bleaching, dental surgery at the enamel-cementum border, or systemic predisposing factors (13-15).

In this retrospective study, we evaluated the dental injuries of patients who were treated for trauma to their permanent teeth. Our aim was to evaluate the frequency of development of root resorption in cases of dental trauma involving supporting tissue, considering factors such as the type of injury, the patient's age, and the period between dental injury and initial examination.

\section{Materials and Methods}

The study was approved by the Ethics Committee for Research with Human Beings of the School of Dentistry São Leopoldo Mandic (protocol number 2012/0121).

A retrospective study was conducted with reference to the files of patients who had sought treatment for dental trauma at the Dental Trauma Center of the Dentistry School of Piracicaba, State University of Campinas, Piracicaba, SP, Brazil, between April 2010 and June 2012. We investigated 249 traumatized teeth (including teeth with an open apex) of 125 patients aged between 7 and 51 years. All patients were informed about the study and were asked to sign an agreement. Our analysis was based on information about the following factors: gender; patient age at the time of injury; the teeth that had been injured; the type of dental injury; and the period between dental injury and initial examination (ranging from 21 days to over 12 months). Patients with traumatic inju- ries involving only hard dental tissues, those for whom radiographic data were unsatisfactory, or those who had undergone previous endodontic treatment were excluded from the study. Patients with concussion or subluxation were also excluded, since the appearance of sequelae after these types of injuries is unusual (3).

The radiographs were analyzed by two qualified authors, under optimal conditions, using a light-box (Cristófoli, Mourão, Paraná, Brazil) and a magnifying glass large enough to allow binocular observation. The following aspects were identified: presence of total or partial absence of the lamina dura; presence of increased periodontal ligament space; presence of pathologic root resorption, including external inflammatory root resorption, internal inflammatory root resorption and replacement resorption. Examples of radicular resorption are shown in Fig. 1. For the purposes of this study, a previously reported classification was used (3).

The data were collected and statistically analyzed using the SAS software package (SAS Institute, Cary, NC, USA). Cross-tabulations with chi-squared and Fisher's exact test were performed to examine the relationships between the evaluated parameters. Based on this analysis, linear logistic regression analysis was performed to further investigate these relationships $(P<$ $0.05)$.

\section{Results}

For this study, 249 injured teeth of 125 patients were evaluated. The age of the patients at time of injury varied between 7 and 51 years. Only four injured teeth presented an open apex, and these immature teeth showed external inflammatory resorption.

Table 1 shows the relationship between patient age and the period elapsed between the date of injury and initial examination. Injuries occurred most frequently in young patients aged under 14 years (110/249 - 44.2\%). 
Table 1 Relationship between patient age and period from the date of injury until initial examination

\begin{tabular}{lrrrr}
\hline \multirow{2}{*}{ Age } & \multicolumn{4}{c}{ Time interval from the date of injury until the first exam } \\
& $21-90$ days & $3-12$ months & $>12$ months & \multicolumn{1}{c}{ Total } \\
\hline$<14$ years & $73(66.4 \%)$ & $17(15.5 \%)$ & $20(18.2 \%)$ & $110(44.2 \%)$ \\
$15-20$ years & $42(60.9 \%)$ & $7(10.1 \%)$ & $20(29.0 \%)$ & $69(27.7 \%)$ \\
$21-26$ years & $12(38.7 \%)$ & $5(16.1 \%)$ & $14(45.1 \%)$ & $31(12.4 \%)$ \\
$>26$ years & $15(38.5 \%)$ & $15(38.4 \%)$ & $9(23.1 \%)$ & $39(15.7 \%)$ \\
Total & $142(57.0 \%)$ & $44(17.7 \%)$ & $63(25.3 \%)$ & $249(100 \%)$ \\
\hline
\end{tabular}

Table 2 Frequency of inflammatory and replacement resorption in relation to age, time elapsed until initial examination, and type of trauma

\begin{tabular}{|c|c|c|c|c|c|c|c|}
\hline \multirow[b]{2}{*}{ Parameter } & \multirow[b]{2}{*}{$\begin{array}{l}\text { Total } \\
n(\%)\end{array}$} & \multicolumn{2}{|c|}{ Inflammatory resorption } & \multirow[b]{2}{*}{$P$ value } & \multicolumn{2}{|c|}{ Replacement resorption } & \multirow[b]{2}{*}{$P$ value } \\
\hline & & $\begin{array}{c}\text { absence } \\
n(\%)\end{array}$ & $\begin{array}{c}\text { presence } \\
n(\%)\end{array}$ & & $\begin{array}{c}\text { absence } \\
n(\%)\end{array}$ & $\begin{array}{c}\text { presence } \\
n(\%)\end{array}$ & \\
\hline \multicolumn{8}{|l|}{ Age (years) } \\
\hline$<14$ & $110(44.1 \%)$ & $18(16.3 \%)$ & $92(83.6 \%)$ & \multirow{4}{*}{0.7103} & $65(59.0 \%)$ & $45(40.9 \%)$ & \multirow{4}{*}{0.6052} \\
\hline $15-20$ & $69(27.7 \%)$ & $8(11.5 \%)$ & $61(88.4 \%)$ & & $34(49.2 \%)$ & $35(50.7 \%)$ & \\
\hline $21-26$ & $31(12.4 \%)$ & $6(19.3 \%)$ & $25(80.6 \%)$ & & $17(54.8 \%)$ & $14(45.1 \%)$ & \\
\hline$>26$ & $39(15.6 \%)$ & $7(17.9 \%)$ & $32(82.0 \%)$ & & $23(58.9 \%)$ & $16(41.0 \%)$ & \\
\hline \multicolumn{8}{|l|}{ Time elapsed } \\
\hline 21-90 days & $142(57.0 \%)$ & $15(10.5 \%)$ & $127(89.4 \%)$ & \multirow{3}{*}{0.0199} & $83(58.4 \%)$ & $59(41.5 \%)$ & \multirow[t]{3}{*}{0.3154} \\
\hline 3-12 months & $44(17.6 \%)$ & $12(27.2 \%)$ & $32(72.7 \%)$ & & $26(59.0 \%)$ & $18(40.9 \%)$ & \\
\hline$>12$ months & $63(25.3 \%)$ & $12(19.0 \%)$ & $51(80.9 \%)$ & & $30(47.6 \%)$ & $33(52.3 \%)$ & \\
\hline \multicolumn{8}{|l|}{ Type of trauma } \\
\hline Extrusive luxation & $62(24.9 \%)$ & $14(22.5 \%)$ & $48(77.4 \%)$ & \multirow{4}{*}{0.0406} & $59(95.1 \%)$ & $3(4.8 \%)$ & \multirow{4}{*}{$<0.0001$} \\
\hline Lateral luxation & $76(30.5 \%)$ & $15(19.7 \%)$ & $61(80.2 \%)$ & & $49(64.4 \%)$ & $27(35.5 \%)$ & \\
\hline Avulsion & $55(22.0 \%)$ & $6(10.9 \%)$ & $49(89.0 \%)$ & & $7(12.7 \%)$ & $48(87.2 \%)$ & \\
\hline Intrusive luxation & $56(22.4 \%)$ & $4 \quad(7.1 \%)$ & $52(92.8 \%)$ & & $24(42.8 \%)$ & $32(57.1 \%)$ & \\
\hline
\end{tabular}

In these patients, the time interval from the date of injury until initial examination was 21-90 days in most cases $(73 / 110-66.4 \%)$.

Table 2 shows the frequency of inflammatory and replacement resorption in relation to age, time elapsed until initial examination, and type of tooth trauma. Seventy-six teeth showed lateral luxation $(30.5 \%), 62$ (24.9\%) showed extrusive luxation, 48 (77.4\%) showed external inflammatory root resorption, 56 (22.4\%) showed intrusive luxation, and 55 (22.9\%) teeth were avulsed and replanted. Replacement resorption was uncommon, being observed in only three teeth $(4.8 \%)$ affected by extrusive luxation. There was no significant difference between the incidence of external inflammatory resorption $(P=0.7103)$ and that of replacement resorption $(P=0.6052)$ relative to patient age. However, there was a positive relationship between the the development of external inflammatory resorption and the time elapsed after injury until initial examination $(P=0.0199)$. External inflammatory resorption was diagnosed more frequently in patients who sought care within 21 to 90 days after injury (89.4\%) and replacement resorption was diagnosed more often in cases that were treated beyond 12 months after the date of trauma $(52.3 \%)$.

Multiple logistic regression analysis showed that, in comparison with extrusive luxation, cases of intrusive luxation, avulsion and lateral luxation were 3.7, 2.8 and 1.4 times more likely to lead to external inflammatory resorption, respectively (Table 3 ).

In comparison with extrusive luxation, a significantly high incidence of avulsion was found in cases of replacement resorption (134.8 times higher) and intrusive luxation (26.2 times higher). Cases of lateral luxation were 10.8 times more likely to lead to replacement resorption than cases of extrusive luxation (Table 4).

Inflammatory internal resorption and canal calcification were not considered for statistical analysis due to their low frequency. Only 2 teeth $(0.8 \%)$ affected by lateral luxation showed inflammatory internal resorption. No inflammatory internal resorption was observed 
Table 3 Impact of inflammatory root resorption in relation to trauma severity when compared to extrusive luxation

\begin{tabular}{lccccc}
\hline Type of trauma & $\begin{array}{c}\text { Total } \\
(\%)\end{array}$ & $\begin{array}{c}\text { Presence of inflammatory resorption } \\
n(\%)\end{array}$ & Odds Ratio & IC 95\% & $P$ value \\
\hline Extrusive luxation & $62(24.9 \%)$ & $47(77.4 \%)$ & 1 & & \\
Lateral luxation & $76(30.5 \%)$ & $61(80.2 \%)$ & 1.4 & $0.605-3.422$ & 0.0286 \\
Avulsion & $55(22.0 \%)$ & $49(89.0 \%)$ & 2.8 & $0.981-8.189$ & 0.0330 \\
Intrusive luxation & $56(22.4 \%)$ & $52(92.8 \%)$ & 3.7 & $1.129-12.273$ & 0.0133 \\
\hline
\end{tabular}

Table 4 Impact of replacement root resorption in relation to trauma severity when compared to extrusive luxation

\begin{tabular}{|c|c|c|c|c|c|}
\hline Type of trauma & $\begin{array}{l}\text { Total } \\
n(\%)\end{array}$ & $\begin{array}{c}\text { Presence of replacement resorption } \\
n(\%)\end{array}$ & Odds Ratio & IC $95 \%$ & $P$ value \\
\hline Extrusive luxation & $62(24.9 \%)$ & $3(4.8 \%)$ & 1 & & \\
\hline Lateral luxation & $76(30.5 \%)$ & $27(35.5 \%)$ & 10.8 & $3.100-37.881$ & $<0.0001$ \\
\hline Avulsion & $55(22.0 \%)$ & $48(87.2 \%)$ & 134.8 & $33.085-549.687$ & $<0.0001$ \\
\hline Intrusive luxation & $56(22.4 \%)$ & $32(57.1 \%)$ & 26.2 & $7.327-93.844$ & $<0.0001$ \\
\hline
\end{tabular}

in other types of trauma. Calcification of the canal was identified in only $16(6.4 \%)$ teeth, for which the initial examination had been conducted more than 12 months after dental injury in most cases.

\section{Discussion}

The present study has yielded detailed information about the development of root resorption in cases of dental trauma to supporting tissue based on a retrospective analysis of radiographic images. The results revealed that almost $84.9 \%$ of the pathological resorption was represented by external inflammatory root resorption and was present more frequently in cases of intrusive luxation. These results are consistent with previous findings (16-20) and are related to the higher rate of injury to periodontal structures in comparison to extrusive or lateral luxation. The high frequency of external inflammatory resorption observed in cases of lateral luxation and extrusive luxation contradicts the findings of Hecova et al. (20), who found that it occurred in only $11.6 \%$ and $5.6 \%$ of such cases, respectively. However, it is important to emphasize that the present study included only cases in which at least 21 days had elapsed between trauma and initial examination. Accordingly, this time interval is considered significant for the appearance of root resorption (21), as resorption can be diagnosed more accurately at least three weeks after trauma (22).

Previous studies have reported that internal inflammatory resorption injuries rarely occur in the most severe cases of luxation $(23,24)$, and this was also found in the present study. This is probably not surprising because this type of resorption requires pulp vitality to provide nutrients to the odontoclasts, and one of the most common sequelae in this type of trauma is pulp necrosis $(20,25,26)$. In the present study, pulpal calcifications were observed at a lower frequency, ranging from $5.3 \%$ to $9.6 \%$, in comparison to $15 \%$ to $86 \%$ in previous studies $(20,25,27)$. This is because pulp canal calcification is usually observed within one year after trauma and the majority of previous studies covered a longer time frame than the present study. This difference can also be explained in terms of sampling, since the risk of pulp canal calcification is greater in immature teeth (25), which accounted for only a small proportion of the samples used in the present study.

Another significant factor related to the development of root resorption is patient age $(18,25)$. Root resorption is more frequent in young patients, and its incidence also increases in proportion to the time elapsed between the date of trauma and initial examination. Although the latter parameter was the only one found to be significanty related to external inflammatory resorption in the present study, previous investigations have shown that, like age, it does not influence the incidence of replacement resorption, suggesting that the type of tooth injury is the most significant factor affecting the incidence of root resorption. Resorption was found irrespective of the period elapsed after injury, and was present in both young and mature adult patients, suggesting that the severity of the trauma has more more relevance to the development of root resorption than factors such as time elapsed or patient age. External inflammatory resorption, on the other hand, develops more quickly than earlier replacement resorption, which might account for the impact of the time factor on the incidence of external inflammatory resorption. Despite the low proportion of immature teeth 
examined in this study, all patients had inflammatory external root resorption, in accordance with previous studies $(9,27,28)$ indicating the faster development of root resorption in young individuals.

Through regression analysis, the risk of development of root resorption after different types of trauma was investigated. The incidence of external inflammatory resorption was higher in teeth that had suffered intrusion, corroborating previous findings $(9,16,20,25,26)$. A high incidence of external inflammatory resorption is also a factor associated with the low incidence of pulp canal calcification, since this requires a viable pulp (24). A higher frequency of external inflammatory resorption was also evident $(70 \%)$ in comparison with replacement resorption (30\%). As discussed previously, the severity of injury to the supporting tissue in cases of intrusion is the main factor associated with the development of inflammatory external resorption. With regard to replacement resorption, the incidence was higher in cases of avulsion in comparison to luxation, which is in agreement with several authors $(17,29)$. In cases of avulsion and replantation, the frequency of replacement resorption is greater than that of external inflammatory resorption. Absence of the periodontal ligament can stimulate bone cells to form new tissue, remodeling the traumatized area. Despite the fact that damage to the periodontal ligament is significant in cases of intrusion, these areas are small when compared to avulsed teeth. It has been reported that root resorption is 16 times more probable in replanted teeth, when related to mobility impairment, and that the longer the period of replantation, the higher the chances of replacement resorption occurring (28).

Previous clinical studies $(20,28)$ were concerned with early diagnosis of root resorption in cases of dental trauma in order to provide a better prognosis for the traumatized tooth. The present study examined the importance of clarifying the diagnosis of root resorption in relation to patient age, the time elapsed from trauma until receipt of emergency services, and especially the type of injury. Early diagnosis of these types of sequelae improves the prognosis and provides a lifeline for the tooth. It can be concluded that root resorption is observed more often and that its development risk is higher in instances of severe trauma, especially avulsion and intrusive luxation. Therefore, the type of trauma can be considered a factor determining the development of root resorption.

\section{References}

1. Borssén E, Holm AK (2000) Treatment of traumatic dental injuries in a cohort of 16-year-olds in northern Sweden. Endod Dent Traumatol 16, 276-281.
2. Skaare AB, Jacobsen I (2003) Dental injuries in Norwegians aged 7-18 years. Dent Traumatol 19, 67-71.

3. Glendor U, Marcenes W, Andreasen JO (2007) Classification, epidemiology and etiology. In: Textbook and color atlas of traumatic injuries to the teeth, 4th ed, Andreasen JO, Andreasen FM, Andersson L eds, Blackwell, Copenhagen, 217-254.

4. Levin L, Samorodnitzky GR, Schwartz-Arad D, Geiger SB (2007) Dental and oral trauma during childhood and adolescence in Israel: occurrence, causes, and outcomes. Dent Traumatol 23, 356-359.

5. Wright G, Bell A, McGlashan G, Vincent C, Welbury RR (2007) Dentoalveolar trauma in Glasgow: an audit of mechanism and injury. Dent Traumatol 23, 226-231.

6. Caldas IM, Magalhães T, Afonso A, Matos E (2008) Orofacial damage resulting from road accidents. Dent Traumatol 24, 410-415.

7. Perheentupa U, Laukkanen P, Veijola J, Joukamaa M, Järvelin MR, Laitinen J et al. (2001) Increased lifetime prevalence of dental trauma is associated with previous non-dental injuries, mental distress and high alcohol consumption. Dent Traumatol 17, 10-16.

8. Fasciglione D, Persic R, Pohl Y, Filippi A (2007) Dental injuries in inline skating--level of information and prevention. Dent Traumatol 23, 143-148.

9. Andreasen FM, Pedersen BV (1985) Prognosis of luxated permanent teeth--the development of pulp necrosis. Endod Dent Traumatol 1, 207-220.

10. Robertson A (1998) A retrospective evaluation of patients with uncomplicated crown fractures and luxation injuries. Endod Dent Traumatol 14, 245-256.

11. Robertson A, Andreasen FM, Andreasen JO, Norén JG (2000) Long-term prognosis of crown-fractured permanent incisors. The effect of stage of root development and associated luxation injury. Int J Paediatr Dent 10, 191-199.

12. Bakland LK (1992) Root resorption. Dent Clin North Am 36, 491-507.

13. Gold SI, Hasselgren G (1992) Peripheral inflammatory root resorption. A review of the literature with case reports. J Clin Periodontol 19, 523-534.

14. Heithersay GS (1999) Invasive cervical resorption: an analysis of potential predisposing factors. Quintessence Int 30, 83-95.

15. Patel S, Kanagasingam S, Pitt Ford T (2009) External cervical resorption: a review. J Endod 35, 616-625.

16. Martin IG, Daly CG, Liew VP (1990) After-hours treatment of anterior dental trauma in Newcastle and western Sydney: a four-year study. Aust Dent J 35, 27-31.

17. Ebeleseder KA, Santler G, Glockner K, Hulla H, Pertl C, Quehenberger F (2000) An analysis of 58 traumatically intruded and surgically extruded permanent teeth. Endod Dent Traumatol 16, 34-39.

18. Andreasen JO, Bakland LK, Andreasen FM (2006) Traumatic intrusion of permanent teeth. Part 2. A clinical study of the effect of preinjury and injury factors, such as sex, age, stage 
of root development, tooth location, and extent of injury including number of intruded teeth on 140 intruded permanent teeth. Dent Traumatol 22, 90-98.

19. Albadri S, Zaitoun H, Kinirons MJ (2010) UK National Clinical Guidelines in Paediatric Dentistry: treatment of traumatically intruded permanent incisor teeth in children. Int J Paediatr Dent 20, Suppl 1, 1-2.

20. Hecova H, Tzigkounakis V, Merglova V, Netolicky J (2010) A retrospective study of 889 injured permanent teeth. Dent Traumatol 26, 466-475.

21. Andreasen JO, Andreasen FM (1993) Textbook and colour atlas of traumatic injuries to the teeth, 3rd ed, Blackwell, Copenhagen, 762.

22. Eveson JW, Gibb DH (1989) Multiple idiopathic internal resorption. Br Dent J 166, 49-50.

23. Andreasen JO, Andreasen FM (1992) Root resorption following traumatic dental injuries. Proc Finn Dent Soc 88, Suppl 1, 95-114.

24. Wigen TI, Agnalt R, Jacobsen I (2008) Intrusive luxation of permanent incisors in Norwegians aged 6-17 years: a retro- spective study of treatment and outcome. Dent Traumatol 24, 612-618.

25. Oginni AO, Adekoya-Sofowora CA (2007) Pulpal sequelae after trauma to anterior teeth among adult Nigerian dental patients. BMC Oral Health 7, 11.

26. Neto JJ, Gondim JO, de Carvalho FM, Giro EM (2009) Longitudinal clinical and radiographic evaluation of severely intruded permanent incisors in a pediatric population. Dent Traumatol 25, 510-514.

27. Soares AJ, Gomes BPFA, Zaia AA, Ferraz CCR, Souza-Filho FJ (2008) Relationship between clinical-radiographic evaluation and outcome of teeth replantation. Dent Traumatol 24, 183-188.

28. Kinirons MJ, Gregg TA, Welbury RR, Cole BOI (2000) Variations in the presenting and treatment features in reimplanted permanent incisors in children and their effect on the prevalence of root resorption. Br Dent J 189, 263-266.

29. Werder P, von Arx T, Chappuis V (2011) Treatment outcome of 42 replanted permanent incisors with a median follow-up of 2.8 years. Schweiz Monatsschr Zhanmed 121, 312-320. 